\title{
GRID SHELL DESIGNING AND CONSTRUCTION TECHNOLOGY OF GLUE-LAMINATED LATHS
}

\author{
TÕNIS TEPPAND ${ }^{1}$, PEEP NURME $^{2} \&$ SIIM TEPPAND $^{3}$ \\ ${ }^{1}$ Department of Rural Building, Institute of Forestry and Rural Engineering, \\ Estonian University of Life Sciences, Estonia \\ ${ }^{2}$ Department of Rural Building, Institute of Forestry and Rural Engineering, \\ Estonian University of Life Sciences, Estonia \\ ${ }^{3}$ Crepidoma OÜ, Estonia
}

\begin{abstract}
CAD/FEM/CAM software is used to design the 3D model of grid shell. The longitudinal length of the laths is measured along the curved side. The position of the crossing nodes $(\mathrm{x}, \mathrm{y}, \mathrm{z}$; different on each lath) is used to produce the half lap joints at exact places by CNC-workstations on straight laths. The laths will be connected by half lap joints with half-dovetailed joints (without metallic fasteners) to bear internal forces from the top of the shell to the edges. There is no more need for excessively long laths. The length is limited only by the cross-sectional measure of the lath capable to carry the dead weight of the cantilever laths themselves while supported only from the first and second crossing node. The laths will be connected longitudinally with a gradual tenon on one end and mortise at the other end. The laths are produced as glue-laminated wood, but in this case of lamellae, they are installed together as multiple hollow square-tubes, one in another. Different species of timber with various physical properties can be used. By gradually displacing the square-tubes of lamellae upwards, starting from the inside layer, the tenon and mortise will be generated during the gluing process. After fixing the first row of laths (inclined with respect to the foundation plane) to the external beam or foundation, the shell structure starts "rising" upwards by connecting the laths longitudinally. Every subsequent layer of laths has mirrored inclination, adding thickness and strength to the grid shell. Laths will be bent and twisted during the assembly process, until the half-dovetailed and half lap joints of two crossing laths lock. The internal forces generated by the bending and torsion of the laths keep the designed shape of the grid shell without any need for additional supports.

Keywords: grid shell, GL, carpentry joints, FEM software, CNC-workstation.
\end{abstract}

\section{INTRODUCTION}

To construct traditional grid-shell the eligible shape will initially be modelled with 3D software. The calculations of load combinations will be done and then the values of inside forces will be found, commonly with FEM (Finite Element Method) software. The dimensions of cross-sections of rods and connecting nodes will be found on the basis of inside forces both between the rods themselves and with rods to supporting structure and/or straight to the foundation.

Already from the Mannheim Multihalle (by Frei Otto, 1975) and later the Savill Garden Building, the most commonly used technology to construct grid-shells is where rods, longitudinally glued together with finger joints, are mounted together on different layers on the horizontal platform with loosely fixed nodes, which height is equal to the highest point of initially designed structure. Then the forming of planned grid-shell will start by lowering down needed sections/parts with construction jacks [1].

The technical problems lie in the fact that the shell cannot be built exactly according to the original design. Therefore, the calculated inside forces found at first will change and that can lead to under-dimensioning the elements and in worst case even to collapse later on. The uncertainty of behaviour of timber and/or timber-based structures in unpredictable moisture content should be considered. Inability of assessment of different variables forces to over- 
dimension rods and nodes during design process which also increase material intensity, dead loads and cost. Besides that, in traditional technology, steel plates and numerous bolts are used in connecting nodes of laths to fix but allow movement along the shell surface. Condensate appearing on the metallic parts due to air humidity, together with straight contact to wood causes moisture damages and accelerates the decay of wood. Using metallic fasteners increases the price of structure considerably, because besides additional material, a lot more expensive handiwork hours are needed, which is not possible to be replaced by robots yet.

To avoid the preceding, the grid-shell has to be built with the designed shape straight away. The coordinates $(\mathrm{x}, \mathrm{y}, \mathrm{z})$ of nodes found with software will be used to treat carpentry joints into the laths of grid-shell. Mounting them together they form the originally designed shape of shell with no need for additional metal fasteners.

\section{THE AIM AND ORDER OF ACTIVITIES}

The aim of this paper is to introduce alternative and novel technology of grid-shell modelling, production of construction elements/laths and installation at building site. The purpose is to decrease the cost of construction with reducing material cost together with decreasing amount of time spent designing and constructing.

\subsection{Modelling}

When constructing grid-shell structures, the quality of initial modelling is of crucial importance. Considering that gravity is everywhere, the arc and the vault derived from it in a shell with double-curved surface are structures with the most optimised geometry ever taken into use. Especially with ratio of used materials to useful span. Current 3D CAD software enables you to model optimised curves with different radii. By moving the crossing points, we are able to get an optimal surface with desired parameters as a result. When designing grid-shell structures 3D CAD software (e.g. Rhinoceros) is used which enables to project a flat grid of axis parallel to each other with certain step and crossing angle on the surface of a shell of desired shape shown on Fig. 1.

The nodes of projected grid $(\mathrm{x}, \mathrm{y}, \mathrm{z})$ will be located exactly above the crossing points of the grid on the flat plane. Due to the multi-layered design, each layer of laths will have to be calculated separately by offsetting the shell surface by the distance of cross section minus height of suitable carpentry joint. By measuring the distances between nodes (all are different) we get a dataset which can be used during preparing laths in $\mathrm{CNC}$-workstations. Based on the projected grid a 3D-model of the grid-shell with laths of desired cross-section with carpentry joints at nodes will be generated [2].

Considering the strength and stiffness of the structure it is advisable to shift the axis of different layers of laths along the surface of shell to avoid coincidence of carpentry joints on the bottom and top of the lath to avoid decreasing the cross section too much. The distances between the centres of the nodes and crossing angles depend on the shape of the shell and of the height of layers of laths concerning it. After that, the primarily "endless" laths generated during modelling process will be divided into elements according to the projected spline and the physical properties of lamellae to produce them. The length of the laths is determined by the parameters of cross-section and maximum bending strength depending of the physical properties to maximum cantilever placement when the lath is fixed only from one supporting node. The collected data is converted into $\mathrm{CNC}$-machine-readable format where final processing will be done for partial crossing half lap joints. All laths will be supplied with an ID-number to facilitate assembly at building site. 


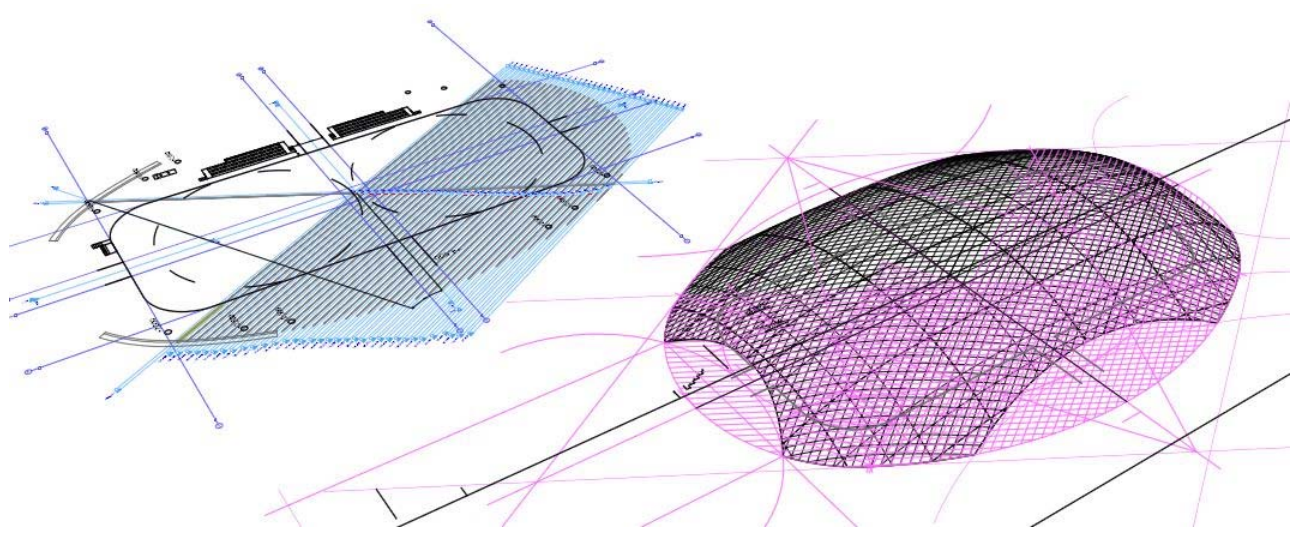

Figure 1: Modelling grid-shell with software Rhinoceros [2].

\subsection{Calculating the model to the strength}

The geometrical and mathematical 3D model of the grid-shell obtained through this method combined with strength calculations (FEM) enables precise dimensioning and configuration of laths and connection nodes.

\subsection{Construction elements - laths of concentrically combined laminated timber}

For lath production, lamellae of different physical properties and same length will be used. They are glued together under press in a multy-layer configuration placed concentrically. The pressing direction is diagonal to the square or rectangular cross-section. Forming joints for longitudinal connection of the laths will not use mechanical proccessing of material. Tenon and mortise will be formed by shifting the layers of lamellae gradually in respect to each other during the gluing and pressing process when the glue still has preserved its plasticity (4-6 min). The gradual tenon on one end and mortise on the other end will be formed at the same time.

The self-locking mounting joints (one sided partial half lap dovetail joint) to connect different layers of the grid-shell structure are made in cnc-workcentres into laths already supplied with end joints. The position and angle of joints (different for every node) come from the primary model geometry. The depth of the joint can be through multiple lamellae, depending on the parameters of loading combinations and inside forces of the structure.

The sizes and tolerances of joints depend on physical propertis of laths - the bending stiffness and modulus of elasticity. On inside forces found on the basis of loading combinations and pre-stress generated during installation by the double-curved axis.

\subsection{Mounting grid-shell on the building site}

Installation of grid-shell starts by fixing the end points of laths of the first two layers to the foundation and/or to the supporting edge element. The length of the elements vary - a halflength element alternates with a full-length element so the longitudinal connections are dispersed. The straigh laths need to be bent until the joint locks. The bending and torsional stress springing up trying to restore the initial shape ensure forming the shell as originally designed. After mounting the first row of crossing laths along the perimeter, the laths are 
extended longitudinally using the stepped tenons and mortises formed during gluing. The tenon will be pressed into mortise or mortise on tenon depending on the mounting order and position. Additional metal or other artificial material fasteners are not used because the laths are also fixed by the the crossing node joint.

After installing second row of the first two layers, the installation of third and fourth row will begin. Mounting of different layers in a stepped fashion will continue until the whole span is covered. Depending on the grid-shell shape, span, cross-section of the glue-lam laths and physical properties of materials used as lamellae the number of layers can be more or less than four, but not less than two.

If the shape of shell requires, additional fixing of layers can be achieved with adding round timber pins. The forming shell structure is mostly self supporting due to the pre-stress in it and requires minimal or no supports depending on computational scheme and calculation methods of carrying capacity of the structure during ongoing construction.

\section{PRODUCTION TECHNOLOGY}

\subsection{Structure of glue-laminated laths}

The production proccess of timber-based lath elements starts with producing equal length lamellae of desired thickness and width. To glue them together, a jig (Fig. 2) is used to place lamellae, covered with glue on one side, at a $45^{\circ}$ angle in relation to pressing direction. When pressing, a similar angle is used on top. Different species of wood can be used in different layers, depending on desired properties of laths.

To increase elasticity of laths, a strong core is surrounded by a layer of smaller elastic modulus and then layers which are successively stronger and stiffer. Dimensions of laths and lamellae they consist of can vary depending on what properties are needed for the grid-shell in mind - its size, elevation angle, pre-stress generated during assembly etc.

\subsection{Glue and gluing}

The glue-lam laths made for bending and compression test performed so far used PVA timber glue "Eskaro B3" (corresponding to stress class D4 by standard EN204 - thermoplastic glues for timber). The temperature during gluing was $17-18^{\circ} \mathrm{C}$. Glue was applied on one wider side with 70 and $100 \mathrm{~mm}$ brushes. The laths of cross-section $80 \times 80 \times 1400 \mathrm{~mm}$ were held under distributed load of 180-207 bar for 45min and left to dry for 24h [3].

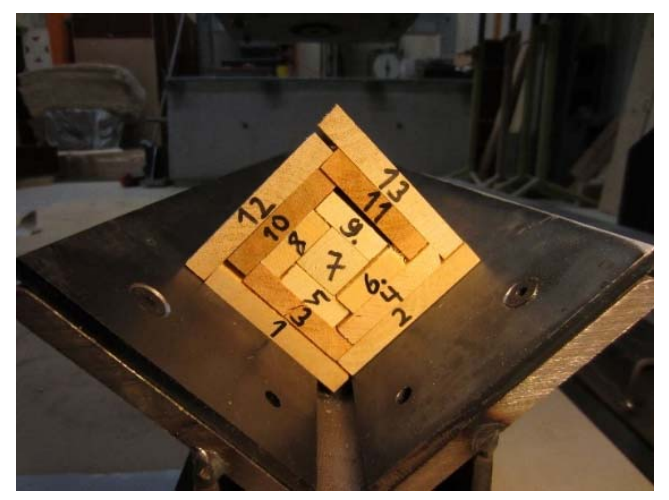

Figure 2: Lamellae placed into the jig in correct order [3]. 
On V-series of test specimens only compression was applied to glued lamellae. For Sseries the concentric layers were shifted longitudinally before final compression, increasing the tackiness of glue connection by increasing diffusion of glue in lamellae contact surfaces.

\subsection{Formatting longitudinal joints}

For longitudinal connection in grid-shell structure a tenon (Fig. 3) is used on one end and mortise (Fig. 4) on the other end. They are formed simultaneously by using a stamp, pressing lamellae from one end under partial pressure to form required stepped configuration. The longest part of the tenon is formed by the central lamella, the next step by the second layer and so on.

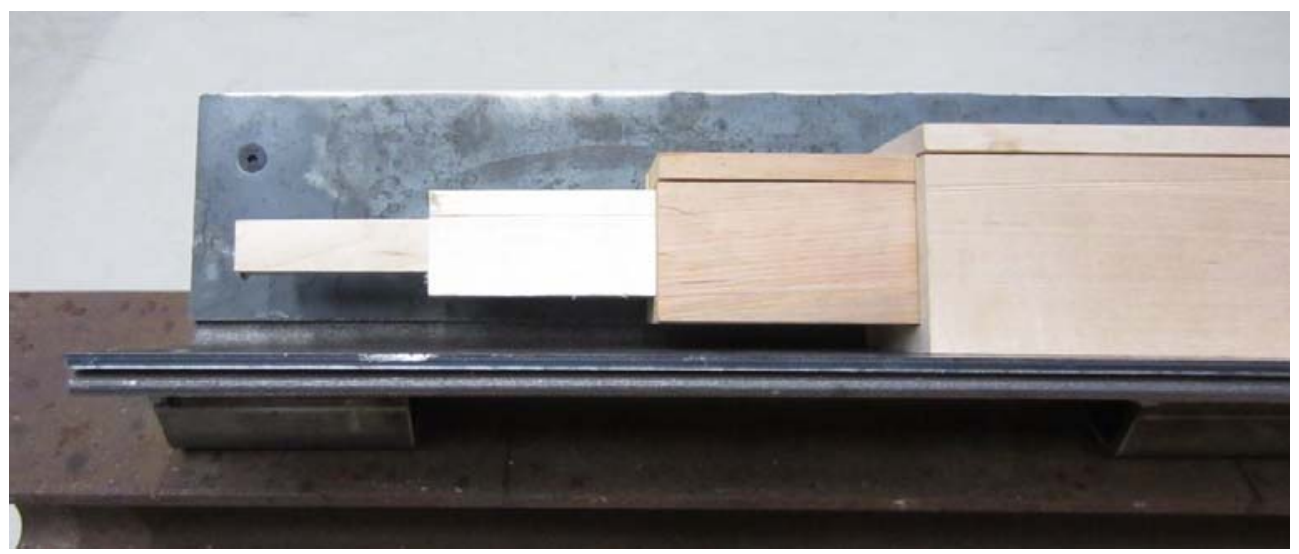

Figure 3: Formatted gradual tenon of different layers of concentric lamellae [3].

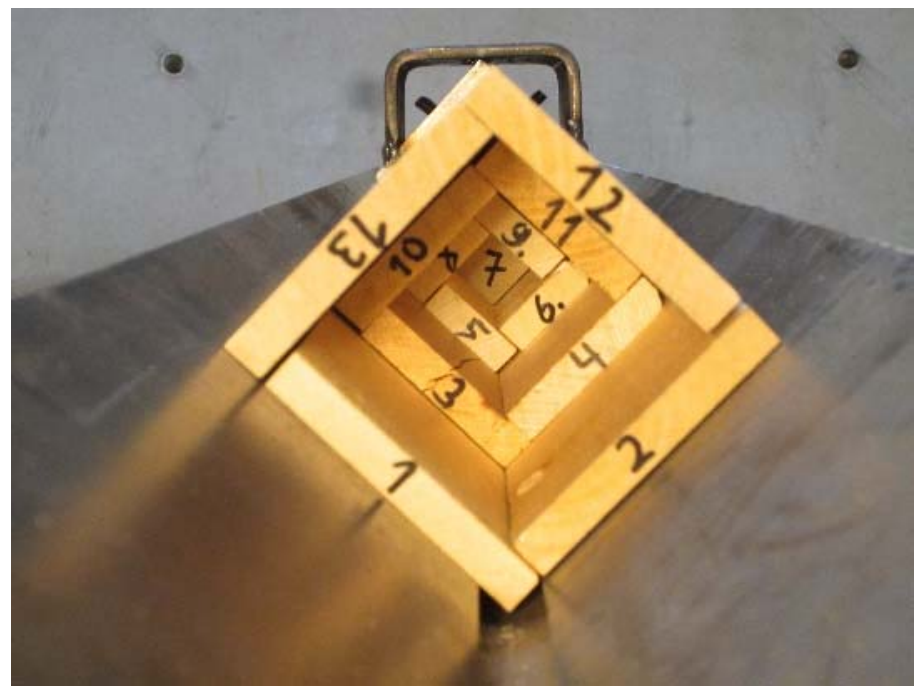

Figure 4: Formatted gradual mortise of different layers of concentric lamellae [3]. 


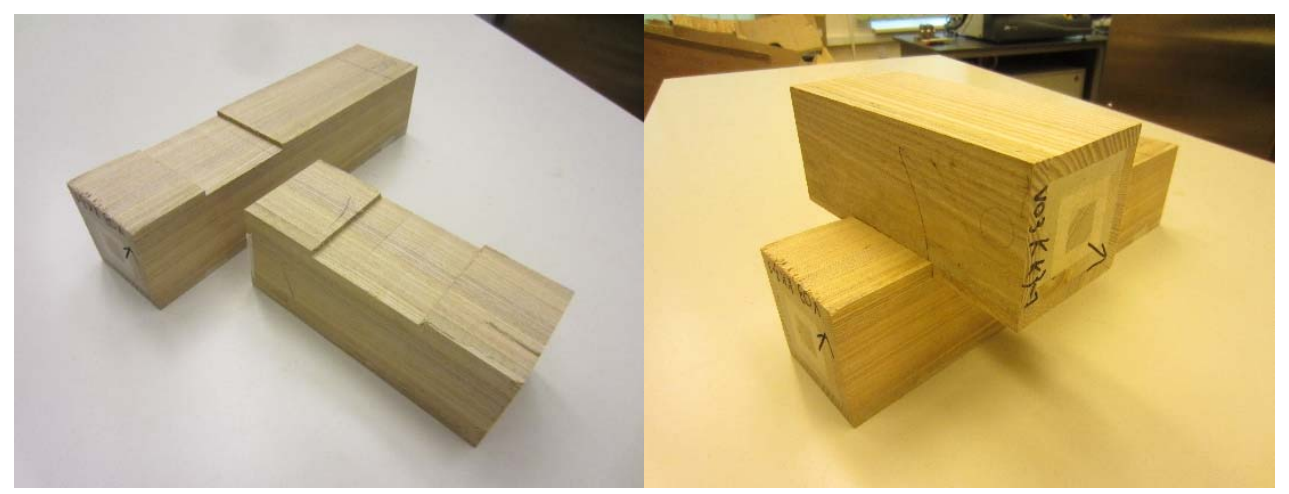

Figure 5: Routed partial half lap joint details. Separately on the left side and mounted together on the right side [3].

\subsection{Carpentry joints for diagonal connections}

For the interconnection of laths and transference of inside forces of structure layers a partial half lap joint is used (Fig. 5). One edge can be formed as a dovetail to ensure self-locking under torsion during installation and after. Carpentry joints are made using mechanical treatment by routing the recess.

\section{PROPERTIES OF LATHS}

The physical properties of glued laths and their carpentry joints depend of glue, species of wood used as lamellae and production technology. The properties of laths of different combinations of lamellae were found with strength test on V-series laths on bending machine Instron 3369.

\subsection{Lamellae}

The species of wood used in lamellae of tested specimen: oak, ash, birch, alder and aspen. The lamellae were cut from bigger bars with circular saw, planed and pre-cut into length of $1400 \mathrm{~mm}$. The cross-section dimensions of used lamellae (from inside to outside): 20x20mm, 10x30mm, 10x50mm, 10x70mm [3].

\subsection{Gluing}

Glue connection quality determines the cohesive strength of lamellae and bending strength of the lath as a whole, but on the other end, glue, pushed too deep into the wood makes it brittle, which decreases the bending strength. On that basis, hot gluing was not used. The mode of failure of bending, compression and lap joint tests showed that the lamellae were first to give in and only after that the glue connection. That also confirms similar tests conducted in Estonian University of Life Sciences of wood-glue-wood connections. An example of glue connection after a destructive test seen by electron microscope Quanta 250 of Groupe ESB École supérieure du bois (Nantes, France) shown on Fig. 6 [4].

For better adhesion, S-series specimen layers were shifted in respect to each other from 95-260mm (from outside to inside, depending on layer). 


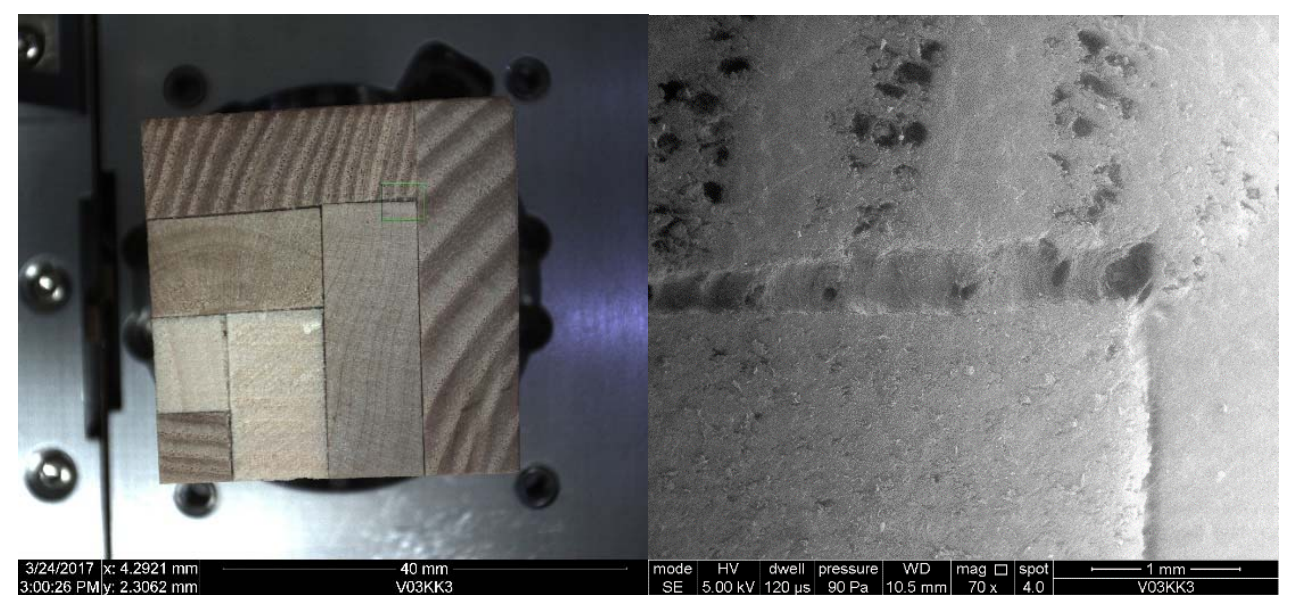

Figure 6: Glue after a destructive test. $1 / 4$ of specimen on the left side and glue between birch (lower left) and ash on the right side [4].

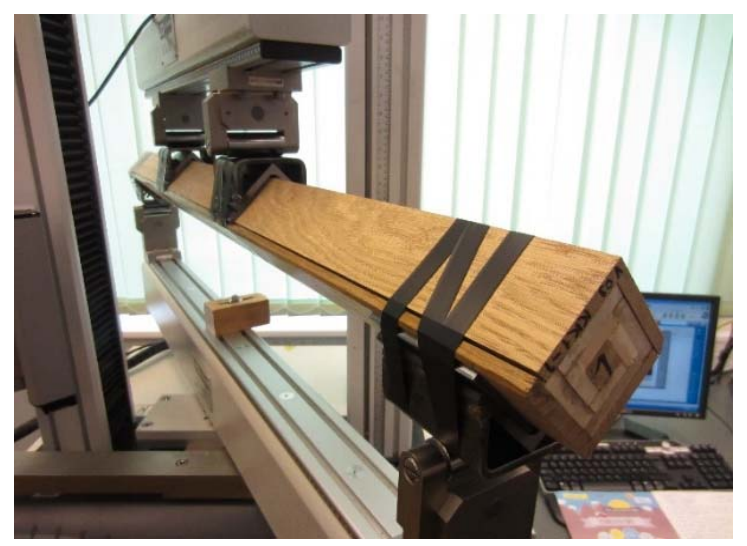

Figure 7: Lath on the special supports at $45^{\circ}$ angle [3].

\subsection{Bending strength, max deflections and plastic deformations}

Considering the inside forces generated in the laths of a grid-shell are multi-directional, the bending tests were done as two point loading (distance between loading points: $410 \mathrm{~mm}$ ) from the diagonal direction of cross-section as a diamond shape, with a span of $1230 \mathrm{~mm}$ (Fig. 7).

$100 \mathrm{~mm}$ supports were put on top of supports of the test machine to keep the specimen at a $45^{\circ}$ angle in respect to applied force. The same supports were put on top of the specimen. The mean results of destructive tests of $\mathrm{V}$-serie specimens are shown at Fig. 8. The blue line on the graph shows the mean breaking of solid spruce reference group V02 KK1 at 12812N. The best result were given by group V03 KK2 (violet line: oak + alder + oak + ash) at an average breaking force of $38180 \mathrm{~N}$, being 3,14 times stronger than solid spruce.

In grid-shell structures, in addition to bending strength, elasticity is especially important - ability to work like a leaf spring under large loads. In our tests it's best reflected in plastic 
deformation after releasing specimens from under load (automatically by Instron 3369). After lower external lamellae broke, the laths restored themselves close to their original shape. (Table 1).

\subsection{Compressive tests for partial half lap joints of size $80 \times 80 \times 5 \mathrm{~mm}$}

To find out the properties of the partial half lap joint at crossing nodes, additional destructive tests were carried out. Horizontal detail, which was joint to vertical detail through the joint, was loaded from two points. To avoid opening the joint, the details were loosely fixed with steel plates $(10 \mathrm{~mm})$ and M12 bolts so the elements could still move. The plates were supported so they would not move with the assembly under load (Fig. 9).

The assembly was set up so the load would radially transfer to the flat lamella at first and tangentially to the vertical lamella secondly.

The mutually loaded joint area was $80 \times 5 \mathrm{~mm}$ or $400 \mathrm{~mm}^{2}$. The mode of failure of both details is shown on Fig. 10.

The mean graphs of failure loads and maximum deflections of partial half lap joints on the laths of different combinations of lamellae are shown on the graph at Fig. 11 and mean plastic deformations on Table 2 .

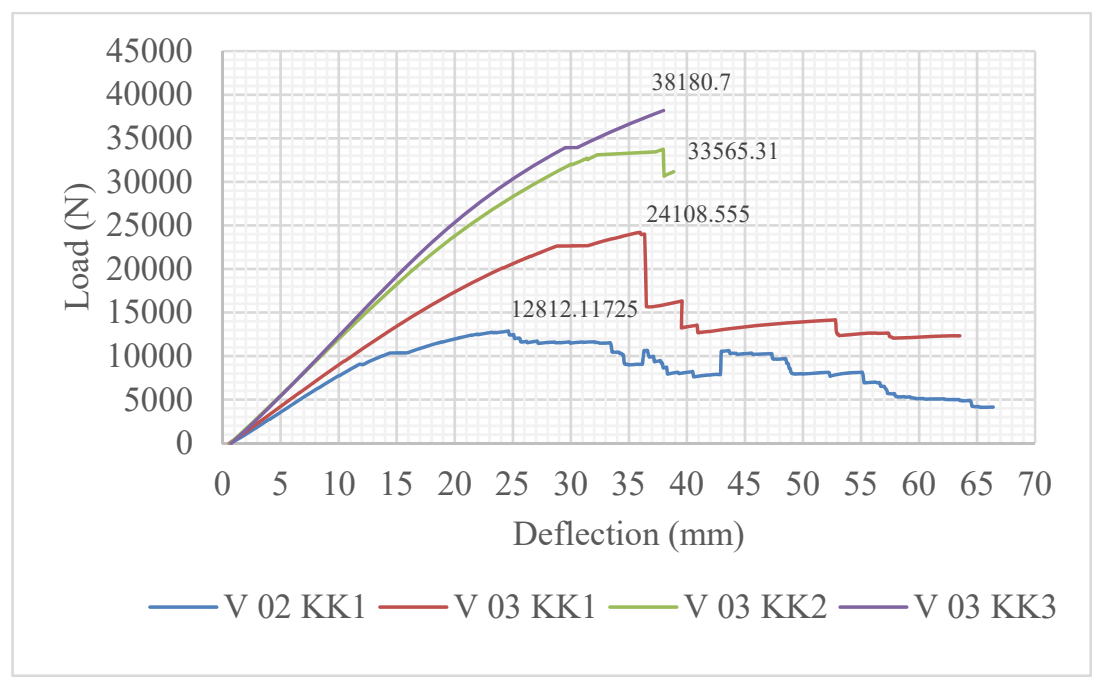

Figure 8: Mean results of failure load and maximum deflection of bending tests [3].

Table 1: Mean results of bending tests on $1230 \mathrm{~mm}$ span of V-series specimens [3].

\begin{tabular}{|l|l|c|c|c|}
\hline $\begin{array}{l}\text { Name of } \\
\text { Specimen } \\
\text { group }\end{array}$ & $\begin{array}{l}\text { Description of } \\
\text { specimen group (layers } \\
\text { from inside to outside) }\end{array}$ & $\begin{array}{c}\text { Failure } \\
\text { load [N] }\end{array}$ & $\begin{array}{c}\text { Max } \\
\text { deflection } \\
{[\mathrm{mm}]}\end{array}$ & $\begin{array}{c}\text { Plastic } \\
\text { deformation } \\
{[\mathrm{mm}]}\end{array}$ \\
\hline V 02 KK1 & Spruce (solid) & 13516 & 48,48 & 23,05 \\
\hline V 03 KK1 & Oak, aspen, birch, oak & 24240 & 51,65 & 11,00 \\
\hline V 03 KK2 & Oak, alder, oak, ash & 34528 & 35,58 & 4,03 \\
\hline V 03 KK3 & Ash, aspen, birch, ash & 36394 & 33,77 & 4,72 \\
\hline
\end{tabular}




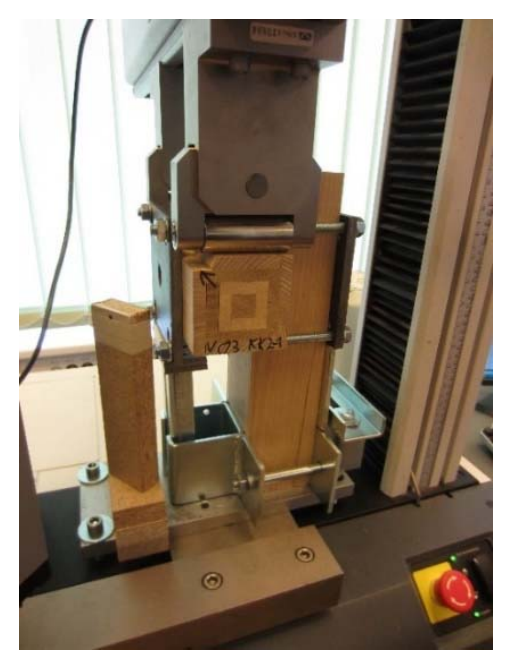

Figure 9: Specimen in the jig for compressive tests of carpentry joint [3].
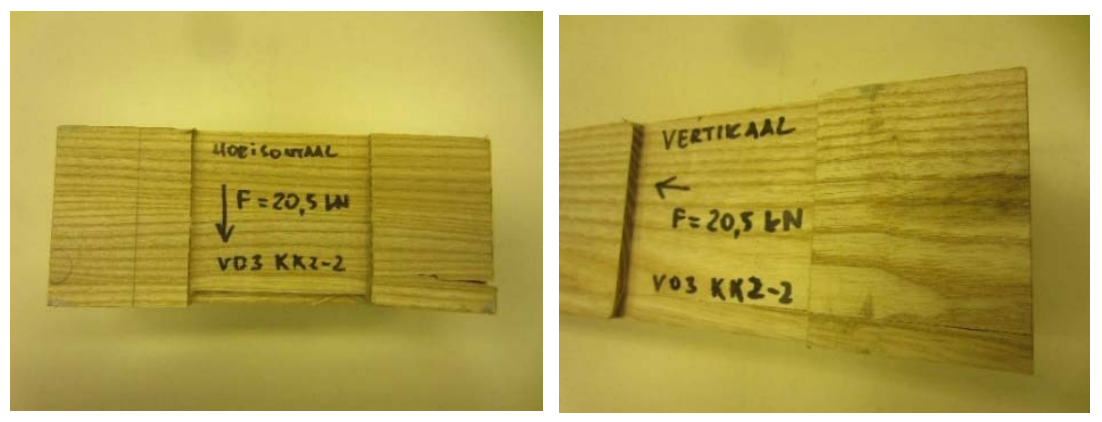

Figure 10: Mode of failure. Horizontal specimen on the left and vertical specimen on the right after compressive test of carpentry joint [3].

The graph shows a gradual load curve - with increasing load the inside forces relocate, restoring the capacity to recieve load.

\section{CONCLUSIONS}

The grid-shell addressed in this paper can be used as an independent structure, covered with panels or as a supporting structure for formwork to cover with primarily plastic and later petrifying materials, or as a composite structure where the laths are at the same time completely or partially elements of interior design due to possible different exclusive species of wood used as the exterior layer. Covering with additional materials (reinforced or not), taken into consideration the maximum load bearing capacity of the structure during coating, will eventually increase the load bearing capacity of the structure with each added layer until the required parameters are met.

According to tests carried out so far with V-series specimens (only pressed, not shifted during gluing) it can be said that the bending strength of laths with such configuration could 
be increased at least 3 times while at the same time retaining or increasing elasticity compared to solid spruce timber. It is also important to highlight the gradual load curves of all tests which show the relocation of inside forces inside laths to restore its strength even after initial damage.

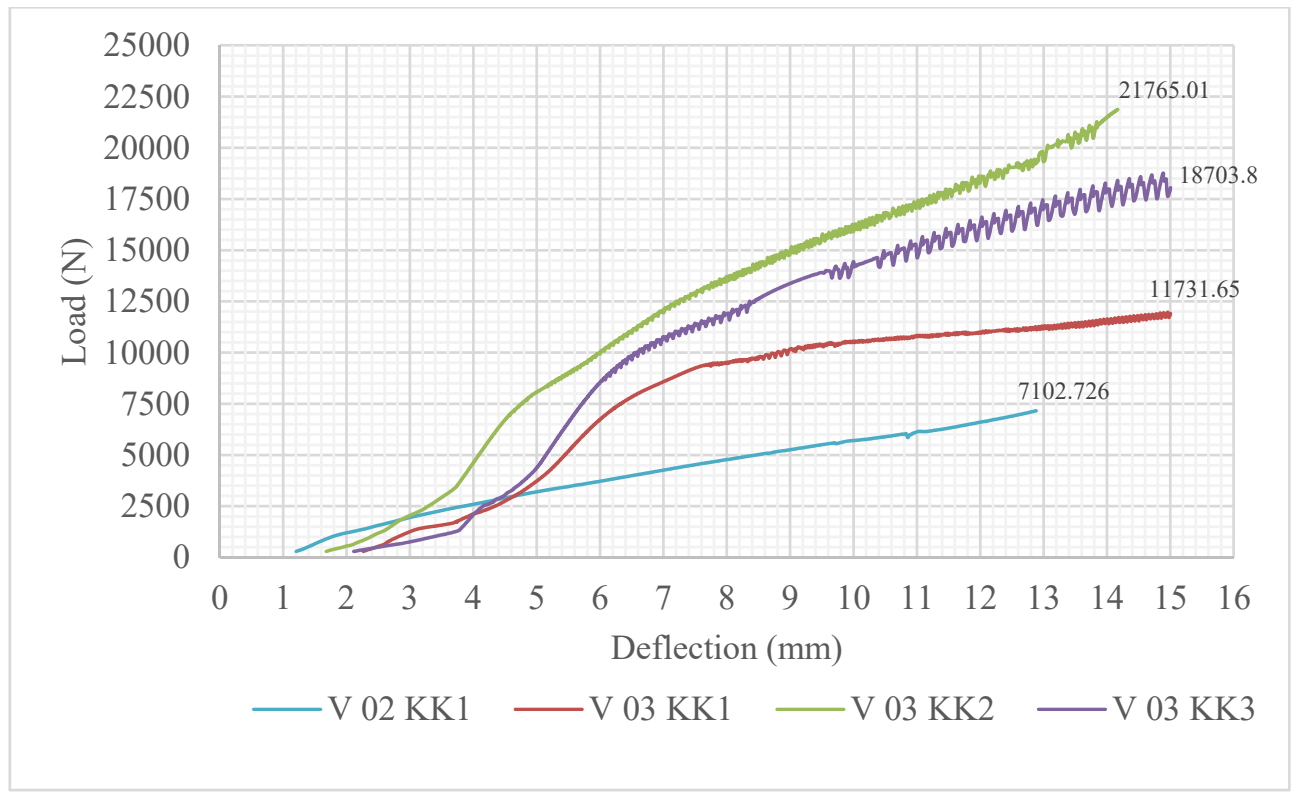

Figure 11: Mean results of failure load and maximum deflection of partial half lap joints [3].

Table 2: Mean results of compressive tests on partial half lap joint of $\mathrm{V}$-series specimens, cross section $-80 \times 5 \mathrm{~mm}[3]$.

\begin{tabular}{|l|l|c|c|c|}
\hline $\begin{array}{l}\text { Name of } \\
\text { Specimen } \\
\text { group }\end{array}$ & $\begin{array}{l}\text { Description of } \\
\text { specimen group (layers } \\
\text { from inside to outside) }\end{array}$ & $\begin{array}{c}\text { Failure } \\
\text { load [N] }\end{array}$ & $\begin{array}{c}\text { Max } \\
\text { deflection } \\
{[\mathrm{mm}]}\end{array}$ & $\begin{array}{c}\text { Plastic } \\
\text { deformation } \\
{[\mathrm{mm}]}\end{array}$ \\
\hline V 02 KK1 & Spruce (solid) & 7102 & 12,87 & 6,83 \\
\hline V 03 KK1 & Oak, aspen, birch, oak & 11971 & 15,04 & 7,09 \\
\hline V 03 KK2 & Oak, alder, oak, ash & 20853 & 14,58 & 7,15 \\
\hline V 03 KK3 & Ash, aspen, birch, ash & 17757 & 15,04 & 9,57 \\
\hline
\end{tabular}

\section{ACKNOWLEDGEMENT}

The patent application P20170011 from $28^{\text {th }}$ of February 2017 is submitted for production technology for laths glued together of lamellae of different species of wood in a concentric configuration and for construction technology of grid-shells built out of them. 


\section{REFERENCES}

[1] Harris, R., Haskins, S. \& Roynon, J., The Savill Garden gridshell: design and construction. The Structural Engineer, 2, pp. 27-34, 2008.

[2] Teppand, T., Teder, T. \& Annama, A., Modelling grid-shell for riding ground. Preliminary design, 2015.

[3] Nurme, P., Teppand, T. \& Teppand, S., Test report: bending and compressing tests of glue-lam laths. Manuscript, Estonian University of Life Sciences, Tartu, Estonia, 2017.

[4] Irle, M., Nurme, P. \& Teppand, T., Test report: examination of the specimen of gluelam laths at macro level. Manuscript, Groupe ESB École supérieure du bois, Nantes, France, 2017. 